\title{
Revisiting Clarence King's "Catastrophism and Evolution" (1877)
}

\author{
Niles Eldredge ${ }^{1}$
}

Published online: 30 September 2019

c) Konrad Lorenz Institute for Evolution and Cognition Research 2019

\begin{abstract}
Published comments by American scientists on Darwin's evolutionary theory are rather rare in the latter half of the 19th century. Clarence King, the founding director of the U.S. Geological Survey in 1879, and an experienced field geologist, focused on the relation between Darwin's evolutionary concepts and the larger context of Hutton/Lyell's uniformitarianism versus Cuvier's catastrophism in his 1877 paper, "Catastrophism and Evolution." King knew that the fossil record contains little or no data supporting Darwin's vision of gradual evolutionary change (indeed, Darwin himself was also painfully aware of that fact). Instead, using horse evolution seen in the rocks of the American West, the very example that by the 1920s had become the shining exemplar of gradual evolutionary change, King argued for catastrophic extinction and evolutionary replacement by "plastic" species that were able to survive in modified form as components of the succeeding biota. Though he could not see such change as involving natural selection, in this novel (for the times, whether in Europe or elsewhere, insofar as I am aware) use of the term "plasticity," there may well be adumbrations of modern evolutionary biology. King's themes became muted as Americans began to embrace more fully Darwin's work. But his version of catastrophism never entirely disappeared, especially in paleobiological circles. And it came back in more fully modern form with force beginning with the work of Norman D. Newell on mass extinctions in the mid-20th century-and with that of two of his students: Eldredge and Gould's (1972) "Punctuated Equilibria." This essay introduces King's "Catastrophism and Evolution" (published in The American Naturalist, vol. 11, no. 8, August 1877, pp. 449-470) for the journal's "Classics in Biological Theory" collection; King's article is available as supplementary material in the online version of this introduction.
\end{abstract}

Keywords American science $\cdot$ Catastrophism $\cdot$ Darwin $\cdot$ Natural selection $\cdot$ Uniformitarianism

Charles Darwin's (1859) Origin of Species became an instant "must read." That was true at home in Britain, of course, where the first print run (2000 copies) was instantly snapped up. But elsewhere as well, perhaps especially in the former North American thirteen colonies-where, by 1859, the U.S. had developed a rapidly maturing and widespread network of scientists employed in universities/colleges, natural history museums, and state and national surveys.

Many mid-19th century American scientists remained circumspectly mute on Darwin's ideas on evolution and the processes underlying evolutionary history. And though the

Electronic supplementary material The online version of this article (https://doi.org/10.1007/s13752-019-00326-6) contains supplementary material, which is available to authorized users.

Niles Eldredge

epunkeek@amnh.org

1 Division of Paleontology, American Museum of Natural History, New York, NY, USA timidity of some, just as in Britain, no doubt lay in their implied collision with Christian beliefs, there were valid intellectual reasons why the details of Darwin's characterization of evolution were resisted to some degree by U.S. biologists and geologists. It is a theme that has persisted pretty much down to the present day.

Statements by American professionals in the 19th century who accepted without doubt the postulate that evolution has occurred and is a valid subject of scientific study-yet had problems with the details-are rare. The problems usually involved the visualization of natural selection occurring as a natural process in the wild. Most interesting are the people who not only accepted evolution, but also agreed that natural selection is a real component of the evolutionary process. But how, when, where, under what circumstances, and especially how quickly or slowly it works, seemed problematic to some early American scientists. That the problem indeed persisted is reflected in my own personal experience 


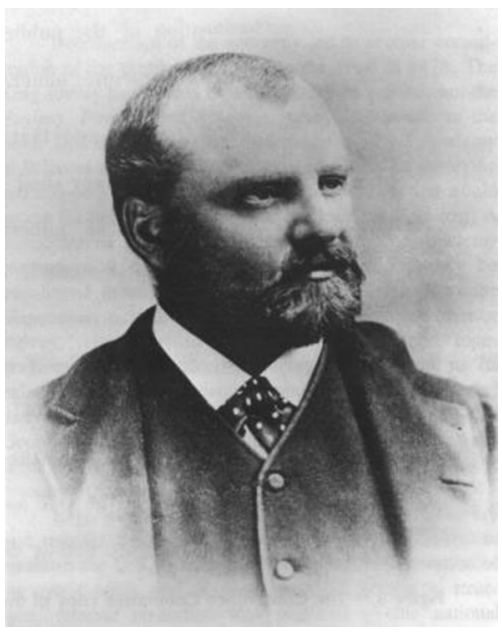

Fig. 1 Clarence King (1842-1901), geologist and first director of the U.S. Geological Survey. Photograph, date unknown, courtesy of Wikimedia Commons

(Eldredge 1971; Eldredge and Gould 1972). Arguments still continue today.

Clarence King (1842-1901; Fig. 1) was one of the few early American scientists who tackled Darwinian evolution head-on—publishing his "Catastrophism and Evolution" in 1877. ${ }^{1}$ King was no biologist. Educated at the Sheffield Scientific School at Yale, in 1867 King persuaded Congress to fund a geological survey of the 40th parallel in the American West under his direction. In 1879 he became the founding director of the newly minted United States Geological Survey-within two years turning the directorship over to John Wesley Powell. He never formally published on biological topics - even on paleontology, with which he had extensive experience as a field geologist. King's (1877) paper is heavy on the geology-so apologies in advance to readers accustomed to a more purely biological diet when reading about evolution!

The United States long ago has assumed a leading role at the forefront of developments in evolutionary theory. The focal point that was to be the progenitor of American thinking in the processes that underlie and generate both biological and geological stasis and change through time lay in the land of the nation's colonial masters: England. Or, rather Great Britain - as the earlier, pre-1859 works of the Frenchmen Cuvier, Geoffroy, Lamarck, the Italian Brocchi and the Englishman Erasmus Darwin were above all grasped

\footnotetext{
${ }^{1}$ For the journal's "Classics in Biological Theory" collection, this essay introduces King's "Catastrophism and Evolution," which was originally published in The American Naturalist, vol. 11, no. 8 (August 1877, pp. 449-470). King's article is available as supplementary material in the online version of this introduction.
}

and further developed in Edinburgh in the late 18th century and early decades of the 19th century by the likes of Hutton, Horner, Jameson, and Grant. Charles Darwin learned his fundamental lessons as a medical student in Edinburgh in the mid-1820s under Jameson and Grant, before honing and expanding them under Sedgwick and Henslow at Cambridge.

Those were the days when science was conceptually sufficiently circumscribed that a bright, eager student was broadly and deeply schooled in all aspects of biology and geology - though each of them of course had their preferences as the early days of specialization were even then fast upon them. I have often thought that Charles Darwin was probably the last of the great thinkers with encyclopedic knowledge of the history of life and of the earth, and with what all his important progenitors and contemporaries thought about these matters (see Eldredge 2015 for the basis of these historical assertions).

The political rupture between the British colonies in North America and their parent was very much like a cultural speciation event. The kernels of inspiration for the nascent growth of the pursuit of knowledge, the establishment in particular of universities, museums, zoos, concert halls, and other institutions, were European. But in detail mostly, and self-consciously deliberately, they were British. The two countries spoke the same language in so many extended respects-most especially in their thinking. The earliest champions of education and all concomitant forms of "higher" culture in the early days of the newly formed United States of America looked to their British cultural parent for their main cues on how to look, act, feel, and actually be civilized.

Yet, from the get-go there were tensions as nascent intellectual life in the fledgling U.S. nation-state sought flight. The earliest American scientists respected, even revered, the more famous, "illustrious" figures in British science: men like Charles Lyell, and soon thereafter, Charles Robert Darwin. Americans craved their approbation even while resenting their often imperial attitudes-and in more than one instance, their avarice and rapacity. The younger nation's scientists were justly proud of their impressive numbers of quarto volumes of "natural history," many the result of state surveys of the biota, rocks, fossils, and agricultural products within their boundaries. Appearing in numbers by the 1840s, the volumes emulated, and were of the same high intellectual standards as those appearing in Britain and continental Europe, such as Darwin's barnacle monographs, and Alcide d'Orbigny's South American volumes, which were largely written and produced in that decade. ${ }^{2}$

\footnotetext{
${ }^{2}$ Darwin's four volumes on barnacles were themselves inspired at least in part by the appearance of the majestic tomes of his rival in South American exploratory biology and geology, d'Orbigny. D'Orbigny, a student of Georges Cuvier, began his South Ameri-
} 
James Hall (1811-1898), the first appointed state paleontologist of New York, was one of the most notable of mid-19th century American scientists. Hall's volume on the geology of the "Fourth District" (western) New York did not appear until 1843-but news of the prodigious exposures (the Silurian section at Niagara Falls topping the list) and fantastic fossils in the Lower-Mid Paleozoic rocks had already spread to European geologists. Charles Lyell, through a speaking grant arranged by Benjamin Silliman at Yale, made the first of his four trips to the U.S. in 1841. Hall was one of the first American scientists Lyell wanted to visit. The two took an excursion from Albany to Buffalo shortly after Lyell's arrival in the U.S.

The interaction between Lyell, Hall, and others, culminating in the "Hamlet Affair" of $1842,{ }^{3}$ provides a vivid snapshot, a microcosm, of the conflicted and often fraught relationship between the best and brightest on both sides of the Atlantic, back in the earliest days of fully professional American natural science.

Lyell, it turns out, had already earned a reputation in his British homeland as something of a poacher on the works and thoughts of others. Even in his centerpiece contribution-the development and promulgation of the concept of "uniformitarianism"--Lyell was thought by many of his colleagues at home to have given short shrift to James Hutton, who was (in fact) the real developer of the idea.

Uniformitarianism (as Gould (1965) and others have pointed out) is two concepts rolled into one: (1) The idea that processes observed taking place in the present are both necessary and sufficient to explain the events of geological and biological history ("The present is the key to the past"ably characterized by Gould as simple induction). And, as a corollary assertion, (2) that the slow rates of processes observed in the present day are sufficient, over the immensities of geological time, to account for the Grand Canyon - or Niagara Falls. Indeed, Lyell went to Buffalo with Hall to check on already calculated rates of retreat of the face of these very Falls. In other words, uniformitarianism asserts that we can safely assume that present-day processes were always active since the Earth was formed, and that they tend

\footnotetext{
Footnote 2 (continued)

can travels five years ahead of Darwin, and Darwin constantly worried that d'Orbigny would scoop him. D'Orbigny may have been the superior observational naturalist and collector, but it was Darwin who came back with a theory of mountain building, coral atoll formation-and of course biological evolution. See Eldredge (2015), p. 182 ff., for more on the relationship between these two men.

3 In what became known as the "Hamlet Affair," Hall publicly castigated Lyell for using data of U.S. scientists to establish a reputation as the expert in North American geology; see Lieberman and Eldredge (2019), "Of Cultural Nationalism, Hamlet and the Cloaca Universalis," for details.
}

to be slow by human perceptual standards - and that these slow-rate processes are all that is necessary to explain the past. It is the assertion that rates are always uniformly slow, especially as projected onto the events of the past, that has always caused the trouble.

That Lyell seemed not to mind the obvious fact that the retreat of the Falls is in largest measure accomplished by sporadic sudden episodes of collapse, in addition to the much slower, grain-by-grain dissolution and micro-spallingoff of the limestone, is a minor but telling crystallization of one of the great disputes of early 19th century science-one with obvious manifestations in evolutionary biology (and geology) down to the present day. Before Lyell jumped in, Georges Cuvier at the Jardin des Plantes in Paris had presented his views on the broad patterns of the history of the Earth and its life. Cuvier had a rivalry within that august Parisian institution with the equally great Jean-Baptiste Lamarck. Lamarck's (1801) volume on invertebrates contains his earliest expression of evolution (transformation)—wherein he claims that only 3\% of the species found in what are now known as Eocene marine limestones of the Paris Basin are still alive in the waters of France's shores. He asserts that the $97 \%$ of those species that disappeared between then and now did so through a process of gradual transformation-rather than Cuvier's preferred explanation that they simply had become extinct. Cuvier saw the history of Earth and life as comprising a series of global mass extinctions, with separate "creations" replenishing life after such catastrophes-hence "catastrophism."

By his own account, Darwin got his gradualism from Lamarck (whom he heaps praise on in his Transmutation Notebook A of late 1837 (Darwin 1987)) — rather than from his older friend and colleague Lyell, from whom Darwin undoubtedly got reinforcement in asserting that gradual change must have been the norm in the evolution of life. Darwin (1987) had a glimpse of the alternative (Notebook $E, 1839)$ when he actually sketched out a version of "punctuated equilibria" in a single phrase-only to reject it in the next (see Eldredge 2015, p. 173). With Darwin firmly on board, the grip of uniformitarianism on the British scientific imagination was cemented.

I am not claiming that there is an inherent difference between British and American science. As Clarence King notes in the present essay (p. 452), we all look at the same set of facts. But I am claiming that some important early signposts-such as the Hamlet Affair in 1842, and King's (1877) paper, show that Americans (and continental Europeans) were much less swayed than were the British by the hypnotic mantra of uniformitarianism as propounded by their most influential scientific leaders. As recently as 1993, British geologist Derek Ager wrote (in the Introduction to his book The New Catastrophism, Ager 1993, p. xv) that one of the advantages of getting older is that, "I am no longer 
afraid of making a fool of myself." That speaks volumes on how strongly the uniformitarian/anti-catastrophism attitude has been entrenched in British scientific thought - at least according to one of its better practitioners. Ager also rather acerbically remarked (p. xvii) that Lyell tended to generalize and theorize, while Cuvier actually looked at the rocks.

So I am saying that newly independent Americans were relatively unfettered by an absolute urge to parrot the presuppositions of their forebears across the Atlantic. This in part explains the somewhat checkered acceptance of Darwin in the early post-1859 years (see Numbers 1998). Though Darwin's evolutionary ideas did of course have their early supporters in the U.S. (Asa Gray perhaps the most eloquent among them), Darwin's dense and detailed summary of the evidence that life has, without doubt, evolved through natural causes nailed the general proposition down once and for all to all who would consider it. (In a reflection of the deep strain of anti-intellectualism permeating U.S. culture since its inception, Americans non-schooled in science are still notorious in their steadfast rejection of evolution, more so than the citizens of most other comparably literate countries.) But it is problems with the rate and pace of evolutionary change, and the relationship between physical environmental change (what King refers to as the "evolution of environment") and the evolutionary process-as well as struggles with the concept of natural selection-that remained fair game for American scientific grappling with Darwin's ideas in those early days. These problems have persisted in somewhat more clarified form right on down pretty much to the present day.

King's essay is the published version of a speech he delivered at his alma mater, the Sheffield School, at Yale that same year. He begins by celebrating America's fulsome embrace of science, notes the Sheffield School's role over the prior 30 years, and (p. 450) proclaims his intent to share "personal thoughts" on the relationship between catastrophism and evolution. The result is an early (possibly the earliest) clear, bold statement of the conflict between strict uniformitarianism and catastrophism in the context of biological evolution published anywhere. Though largely forgotten per se, King's paper sets the tone and tenor of much of American paleontological attempts to grapple with evolution-again, right down to the present day.

The first five pages or so are devoted to his characterizations of catastrophism and uniformitarianism. King reminds his readers that humans have long been aware of the occurrence of catastrophic geological events sporadically intruding on their lives and often causing their deaths. He pronounces the original "universal" catastrophism of Cuvier as dead-unaware that at its grandest scale, mass extinctions will again be seen as global in extent. This is thanks in large measure at first to the revival of interest in mass extinction by the American paleontologist Norman D. Newell, also a
Yale graduate - and mentor to many, including Stephen Jay Gould and myself in the 1960s. Newell never mentioned King in any of his writing, lectures, or conversations, to my knowledge. King's paper seems to have been long forgotten even by us geobiologists by the time the mid-20th century rolled around. It is worth noting that George Gaylord Simpson, the premier mid-20th century paleontological evolutionary theorist, who had hired Newell at the American Museum of Natural History after World War II, somewhat sardonically, if accurately, referred to his junior colleague Newell as a "neo-catastrophist" when Newell started writing about "crises in the history of life" (Simpson 1970, pp. 77-79).

King preferred to see catastrophic events as local and regional in extent - the new (or "neo") catastrophismthough he doesn't use this term. For example, he contrasts the sporadically violent geological history of the American West, so graphically evident in the rocks he studied with his trained geological eyes, with the more placid, slowly paced rates of change he thinks he sees in eastern North America.

If the classic, global catastrophism of Cuvier has been toned down to a more reasonable, empirically based emphasis on local and regional scales, King says that no comparable toning down has as yet occurred on the "universal Uniformitarianism" side of the argumentative ledger: "Sweeping catastrophism is an error of the past. Radical uniformitarianism, however, persists, and probably controls the faith of a majority of geologists and biologists" (p. 454). Earlier (p. 453), in an especially telling comment, King says that uniformitarianism (gradualism) is "accepted with a lover's credulity by nearly all evolutionists..." For this King chiefly blames the British, though he correctly notes as well the influence of Lamarck and Geoffroy among the earlier progenitors.

Persuasively, King (pp. 452-453) points out that, inasmuch as both sides agree "on the facts," meaning that "geological result and the energy to produce it are identical, whichever school is correct," the argument boils down to simply a matter of rates. Catastrophists are comfortable with variable rates - with change often triggered by abrupt events, with longer periods of slow rates producing little or no change. Uniformitarians insist upon slow, steady rates of change-i.e., "gradualism." Intriguingly, King points to empirical evidence that rates can be the product of rapidly occurring events. Today we would point to extraterrestrial bodies impacting the earth, with change coming relatively rapidly to the surviving biota, as an example of truly largescale, global events. The explosion of Krakatoa a decade after King published this paper was a more localized sudden violent event-erasing all traces of life, but soon to be repopulated by recruits from nearby surviving ecosystems.

King, in my view, is right by saying that there is no comparable empirical evidence underscoring the uniformitarian 
perspective of gradual change underlying the production of the same evolutionary results-in both the geological and biological worlds. Instead, uniformitarians, he says (p. 462), "start with a gratuitous assumption (vast time), fortify it by an analogy of unknown relevancy (the present rate), and serenely appeal to the absence of evidence against them as proof in their favor." King expresses his utter disdain for the empty claim that it is the "imperfections of the geologic record" that account for the absence of direct evidence of gradual change. That phrase served as a title for Chapter IX in the first edition of Darwin's Origin. Darwin had plenty of his own data on the importance of geographic isolation in the evolutionary origins of species-and absolutely no compelling fossil evidence for gradualism. I can only conclude (Eldredge 2015) that he could see no way for geographic isolation to occur to serve as a springboard for species evolution over vast continental areas-where, after all, most terrestrial species occur-save the slow rise of mountain ranges (e.g., the Andes in South America). In his defense, little was known about global, regional, and local climate change as an effector of habitat disruption and distributional change.

Thus, part of my own fascination for King's (1877) paper is that he essentially describes the conceptual atmosphere that was still very much present in 1971 and 1972when the initial statements of "punctuated equilibria" first appeared (Eldredge 1971; Eldredge and Gould 1972). This, despite the fact that allopatric speciation, which had been developed first by Theodosius Dobzhansky (1935—a gem of a short, succinct statement), and which takes as its initial empirical basis the observed reproductive discontinuities between closely related species, and their distribution in space, had already been fully incorporated into evolutionary theory. Dobzhansky's paper triggered a flurry of activity, and the concept of geographic pattern in speciation was soon developed more fully by Dobzhansky's (1937) own Genetics and the Origin of Species and in the perhaps even better-known Systematics and the Origin of Species by Ernst Mayr (1942). Though Darwin had indeed grasped the importance of geographic isolation in the evolution of species and concomitant adaptive change, Dobzhansky and Mayr were of course ignorant of the as-yet unpublished contents of Darwin's 1837-1839 Transmutation Notebooks (1987). Yet, even though most evolutionary biologists in the postWWII era of the "modern synthesis" were thus alerted to the importance of geography to evolution, the gradualism they inherited from Darwin when thinking of evolution over time remained unaffected when they thought about patterns of long-term change expected to be observed in the fossil record.

King's own solution to what he reduces to an argument simply over rates of change between uniformitarians and catastrophists is to play King Solomon: there is some truth in both perspectives. Long periods of gradual change in quiescent times (e.g., his version of the rather placid history of eastern North America over much of what is now known as roughly the last half billion years of life on this planet) do plausibly imply gradual rates of biotic change-a milieu where natural selection as Darwin described can come into play. But catastrophic change does occur as well, especially as seen in the American West, with its violent spasms of geological events that drive extinction and subsequent evolution. King had no knowledge of the actual temporal dimensions-yet to be determined until Lord Rutherford introduced radiometric dating using isotopes in the early days of the 20th century. He had no knowledge, likewise, of plate tectonics-and the rather spectacular geological events of the Paleozoic in what was to become eastern North America. He would be perhaps surprised and possibly pleased to hear that the original example of "punctuated equilibria" derives from patterns of stasis and change within a Middle Devonian trilobite lineage of supposedly gently quiescent eastern North America!

All of which connects us to the second important theme of King's (1877) paper: how evolution looks, empirically and theoretically, to a geologist imbued with a catastrophist's perspective. King had a decently correct grasp of Darwin's natural selection. Using some now-quaint terminology, King writes (p. 467) of natural selection that,

analyzed into its component parts, natural selection resolves, as is well known, into two laws, hereditivity and adaptivity: first, the power on the part of organisms to transmit to offspring their own complex structure down to the minutest details; and, secondly, the power by slight alterations on the part of all individuals to vary slightly in order to bring themselves into harmony with a changed environment.

No Malthus here-though King does mention Malthusian struggles near the paper's end (p. 469). And lest the modern reader be inclined to snort at King's suggestion that organisms vary slightly the better to fit in with a changed environment, it is well worth noting that in Darwin's original statement of natural selection in three points (see Eldredge 2005 , p. 8, for an image of this critical passage), Darwin's second point reads, "tendency to small changes (especially with physical change)." King evidently got that from reading, not Notebook E, but rather Darwin's Origin itself. I don't remember stumbling across any such passage in the Origin myself.

And, although Darwin is correctly characterized as seeing the "environment" to which organisms are adapted as primarily biotic, and the competition over resources and mates (sexual selection) as the core of adaptation through natural selection, he was of course keenly aware of the adaptations of organisms to the multiple physical components of the environments in which they lived. 
It is the patterns of biological change and their relationship to physical environmental change (King's "inorganic evolution," or "environmental evolution") that provide his grand conclusion-the second of the two major reasons why King's (1877) paper remains relevant to the present day. This concluding discussion also contains the one major intellectual trouble of the paper-even by the standards of King's day: the use of the word "plasticity." The problem arises, almost ironically, from King swallowing whole Darwin's vision of natural selection necessarily, and exclusively, acting in the slow, steady fashion preferred by Lamarck before him, and Lyell alongside. Darwin was aware that selection could be variable in intensity, but there is no doubt that the "lover's credulity" in the gradualism of evolutionary change over time comes directly and wholly from Darwin himself.

Thus King did not see, or perhaps dare, to suggest that natural selection could be speeded up like the geological processes he knew so much about. If natural selection was at work, it had to be slow, steady, gradual. These days people gently laugh at my own early guesstimate that speciation could take place in "5000-50,000 years of time" - numbers that would be too small for detection in most paleontological settings_certainly including the patterns I interpreted as speciation events in Paleozoic trilobites. We know today it can be much faster than that. I remain in awe of the fact that some biologists have published their conclusions that the coywolves I see in the Adirondacks and suburban New Jersey belong to a full-fledged species that was not known prior to World War I!

So King did not, or could not, allow himself to invoke rapid change through natural selection. But now consider the following passage (pp. 468-469; italics mine):

It is only through rapid movements of the crusts and sudden climatic changes, due either to terrestrial or cosmical causes, that environment can have seriously interfered with the evolution of life. These effects would, I conceive, be, first, extermination; secondly, destruction of the biological equilibrium, thus violating natural selection; and thirdly, rapid morphological change on the part of plastic species.

King's "change or die" scenario invokes "plasticity" on the part of some species. He neither defines the term, nor does he explain how it might lead to rapid morphological change - and thus creates more of a conundrum than a sharply conceived explanatory "black box." We don't quite know exactly what King means by "plasticity." Yet "plasticity" does seem to fit in with King's claim of environmentally directed variation alluded to above, also present in Darwin's then (i.e., as of 1877) unpublished characterization of natural selection - and, interestingly, in the work of some nowcurrent evolutionary biologists (e.g., West-Eberhard 2003).
And, further to King's rescue, I simply point out that if one mentally replaces "die, or change through an inherent plasticity to survive physical environmental events" with "species can either succumb to extinction, remain unchanged, or undergo rapid adaptive change/speciation in abruptly fragmented habitats," you will have the currently received explanation for the same pattern. I cannot help but noting that "biological equilibrium," "rapid morphological change," and of course "natural selection," found in the very same compound sentence with King's "plastic species," are still very much a part of the current lexicon in evolutionary biology. Along with "interaction of energy and matter," King's paper is in some important ways strikingly modern, and reflects concepts still not completely grasped and incorporated by some current paleontologists and evolutionary biologists.

The icing on the cake is in the final paragraph: the rich fossil record of horse evolution in Tertiary rocks of the American West was just becoming known-and many of the key fossils were assembled by O.C. Marsh, again at Yale. T.H. Huxley-whom King acknowledged was the only wellknown biologist/geologist of the day capable of imagining a blend of catastrophism and uniformitarian gradualism - had famously come to visit Marsh and his horses in 1876. The horse story has long since become the iconic example of gradual evolution as seen in the fossil record, memorialized by a now-disassembled famous old exhibition at the American Museum of Natural History developed early in the 20th century that found its way into many a textbook.

King tells us, instead, that, "My own work proves that each new modification succeeded a catastrophe." And indeed, horse evolution was no gradual, linear climb from four toes to one, and so on. It was a branching tree, like that for most other clades. Whatever the climatic changes were that occasioned extinction while fostering isolation and the generation of new species, the current picture of horse evolution is much closer to King's than to Huxley's and Marsh's Darwinian-imbued vision.

King's (1877) paper tells us much about the way things were in the conceptual juxtaposition of the history of life with the physical history of the Earth in the days just after Darwin's Origin appeared in 1859 and quickly came to the United States. Though itself long-forgotten, we nonetheless can read it now and see much of our own understanding and debates 140 + years after King gave his speech at the Sheffield School.

Enjoy!

\section{References}

Ager D (1993) The new catastrophism. Cambridge University Press, Cambridge 
Darwin C (1859) On the origin of species by means of natural selection, or preservation of favoured races in the struggle for life. John Murray, London

Darwin C (1987) Transmutation notebooks B-E, 1837-1839. [See: Kohn D (ed).] In: Barrett PH, Gautrey PJ, Herbert S, Kohn D, Smith S (eds) Charles Darwin's notebooks, 1836-1844: geology, transmutation of species, metaphysical enquiries. Cornell University Press, Ithaca

Dobzhansky T (1935) A critique of the species concept in biology. Philos Sci 2:344-355

Dobzhansky T (1937) Genetics and the origin of species. Columbia University Press, New York

Eldredge N (1971) The allopatric model and phylogeny in Paleozoic invertebrates. Evolution 25:156-167

Eldredge N (2005) Darwin. Discovering the tree of life. Norton, New York

Eldredge N (2015) Eternal ephemera. Columbia University Press, New York

Eldredge N, Gould SJ (1972) Punctuated equilibria: an alternative to phyletic gradualism. In: Schopf TJM (ed) Models in paleobiology. Freeman, Cooper, San Francisco, pp 82-115

Gould SJ (1965) Is uniformitarianism necessary? Am J Sci 263:223-228

King C (1877) Catastrophism and evolution. Am Nat 11(8):449-470
Lamarck J-B (1801) Systême des Animaux sans Vertèbres. Deterville, Paris

Lieberman BS, Eldredge N (2019) Of cultural nationalism, Hamlet and the Cloaca Universalis. In: Macroevolutionaries: the macroevolution blog. https://bronze-sheep-29mh.squarespace.com/ blog/2019/2/27/of-cultural-nationalism-hamletand-the-cloac a-universalis

Mayr E (1942) Systematics and the origin of species. Columbia University Press, New York

Numbers RL (1998) Darwinism comes to America. Harvard University Press, Cambridge

Simpson GG (1970) Uniformitarianism. An inquiry into principle, theory, and method in geohistory and biohistory. In: Hecht MK, Steere WC (eds) Essays in evolution and genetics in honor of Theodosius Dobzhansky. Appleton-Century-Crofts, New York, pp 43-96

West-Eberhard MJ (2003) Developmental plasticity and evolution. Oxford University Press, Oxford

Publisher's Note Springer Nature remains neutral with regard to jurisdictional claims in published maps and institutional affiliations. 